\title{
STUDI HEAT LOSSES PADA ISOBARIC ZONE REAKTOR HYL III DIRECT REDUCTION PLANT PT. KRAKATAU STEEL
}

\author{
Nur Aklis \\ Teknik Mesin Universitas Muhammadiyah Surakarta \\ Jl.A. Yani Tromol Pos 1 Pabelan Kartasura \\ nur_aklis@ums.ac.id
}

\begin{abstract}
ABSTRAK
Isobaric zone merupakan zona untuk mereduksi bijih besi (iron ore) menjadi besi spons (sponge iron) dengan menggunakan gas reduktor $\mathrm{H}_{2}$ di dalam sebuah reactor. Panas dari heater diperlukan untuk membantu proses mereduksi bijih besi pada reactor. Reactor diberi bahan insulasi yaitu refraktori untuk menahan panas yang keluar dan menahan benturan secara langsung dari bijih besi saat proses. Penelitian ini bertujuan untuk mengetahui kerugian panas yang terjadi yang diakibatkan penurunan dari performansi refraktori. Akibat dari panas yang keluar secara berlebihan dapat berakibat merusak dinding reactor hingga menyebabkan kebocoran pada reactor (hot spot). Hasil penelitian dilapangan bahwa pada zona Isobaric temperatur dinding luar reactor mencapai $150{ }^{\circ} \mathrm{C}$, tetapi menurut desain awal temperatur dinding luar reactor pada zona Isobaric adalah $36{ }^{\circ} \mathrm{C}$. Hal ini berarti telah terjadi kerugian panas yang disebabkan oleh adanya perpindahan panas pada reactor yang sudah tidak sesuai dengan desain awal reactor.
\end{abstract}

\section{Kata kunci; Isobaric Zone, Refraktori, Perpindahan Panas}

\section{PENDAHULUAN}

Pabrik Besi Spons (Direct Reduction Plant) menerapkan teknologi berbasis gas alam dengan proses reduksi langsung menggunakan teknologi Hyl. Pabrik ini menghasilkan besi spons (Fe) dari bahan mentahnya berupa bijih besi $\left(\mathrm{Fe}_{2} \mathrm{O}_{3}\right.$ and $\mathrm{Fe}_{3} \mathrm{O}_{4}$ ), dengan menggunakan gas alam $\left(\mathrm{CH}_{4}\right)$ dan air $\left(\mathrm{H}_{2} \mathrm{O}\right)$. Proses mereduksi bijih besi menjadi besi spons terjadi dalam reaktor. Bijih besi yang masuk ke dalam reaktor mengalami proses reduksi yang bertujuanuntuk menghilangkan kadar oksigen pada bijih besi sehingga akan didapat bijih besi dengan kadar Fe 98\%. Proses reduksi di dalam reaktor menggunakan gas $\mathrm{H}_{2}$ sebagai reduktor dengan tekanan 4,55 $\mathrm{kg} / \mathrm{cm}^{2}$ pada temperature $1350{ }^{\circ} \mathrm{C}$. Setelah bijih besi tersebut mengalami proses reduksi maka bijih besi tersebut mengalami perubahan kandungan strukturnya. Bijih besi yang telah mengalami perubahan kandunagan struktur disebut sebagai sponge iron yang akan diolah lagi di dalam furnace menjadi baja.

Proses pada reaktor terbagi dalam tiga ruangan yaitu : Reduction Zone, Isobaric Zone, Cooling Zone. Masing-masing ruangan mempunyai temperatur yang berbeda. Temperatur pada Reduction Zone adalah $1100{ }^{\mathrm{O}} \mathrm{C}$ sedangkan temperature pada Isobaric Zone adalah $1000{ }^{\mathrm{O}} \mathrm{C}$ dan temperatur pada Cooling Zone adalah 450 ${ }^{\mathrm{O}} \mathrm{C}$. Temperatur tinggi di dalam reaktor diperoleh dari gas panas yang berasal dari heater. Di dalam heater, gas reduksi dinaikkan temperaturnya, setelah itu 
ditransfer ke dalam reaktor. Panas yang berasal dari heater dipertahankan agar tidak terjadi kerugian panas yang terlalu besar. Untuk mengurangi kerugian panas, pada reaktor diberikan suatu isolator berupa refraktori. Refraktori tersebut digunakan untuk mempertahankan temperatur pada reaktor. Kualitas yang baik dari refraktori merupakan satu faktor penting yang menentukan proses reduksi biji besi di dalam reaktor. Makin baik fungsi refraktori maka makin kecil heat losses yang terjadi pada reaktor.

Proses reduksi bijih besi pada reaktor sangat mempengaruhi kwalitas refraktori. Dari data di lapangan bahwa temperatur pada dinding luar reaktor sudah tidak sesuai dengan rancangan awal reaktor secara teoritis. Menurut rancangan awal secara teoritis, temperatur dinding luar reaktor dirancang agar tidak membahayakan bagi keselamatan karyawan tetapi dalam kenyataan di lapangan pada dinding luar reaktor telah terjadi over heat sehingga menyebakan proses dari reduksi bijih besi tersebut tidak sempurna selain itu dengan terjadinya over heat pada dinding luar reaktor dapat membahayakan keselamatan bagi operator terutama dalam hal perawatan reaktor.

\section{TINJAUAN PUSTAKA}

Hubungan antara perpindahan panas dan termodinamika

Perpindahan panas adalah ilmu untuk meramalkan perpindahan energi yang terjadi karena adanya perbedaan suhu di antara benda atau material. Ilmu perpindahan kalor menjelaskan bagaimana energi kalor berpindah dari satu benda ke benda yang lain dan meramalkan laju perpindahan yang terjadi pada kondisikondisi tertentu. Apa yang ada dalam perpindahan disebut panas tidak dapat diamati secara langsung, tetapi pengaruhnya dapat diamati dan diukur. Aliran panas seperti halnya pelaksanaan kerja adalah suatu proses dengan mana energi dalam suatu sistem diubah. Cabang ilmu pengetahuan yang membahas hubungan antara panas dan bentuk-bentuk energi lainnya disebut termodinamika.

Perbedaan ilmu perpindahan kalor dengan ilmu termodinamika :

\section{a. Dari sudut pandang termodinamika}

Termodinamika membahas sistem dalam keseimbangan. Ilmu ini dapat digunakan untuk meramalkan energi yang diperlukan untuk merubah sistem dari suatu keadaan seimbang ke keadaan seimbang lain, tetapi tidak meramalkan kecepatan perpindahan itu disebabkan waktu proses perpindahan berlangsung sistem dalam keadaan seimbang. Jumlah panas yang dipindahkan selama proses hanyalah sama dengan beda antara perubahan energi sistem dan kerja yang dilaksanakan. Analisa ini tidak memperhatikan mekanisme aliran panas maupun waktu yang diperlukan untuk memindahkan panas tersebut.

\section{b. Sudut pandang perpindahan panas}

Ilmu perpindahan kalor melengkapi hukum pertama dan kedua termodinamika, dimana dalam hukum pertama termodinamika menyatakan bahwa energi tidak dapat diciptakan maupun dihilangkan tetapi hanya dapat diubah dalam satu bentuk menjadi bentuk lainnya. Hukum kedua termodinamika yaitu bahwa kalor mengalir ke tempat yang lebih rendah dalam skala suhu. Analisa perpindahan panas secara terperinci diperlukan untuk menaksir biaya, kelayakan, dan besarnya peralatan yang diperlukan unutk memindahkan sejumlah panas tertentu dalam waktu yang ditentukan.

\section{Cara-Cara Perpindahan Panas}

\section{a. Konduksi}

Adalah proses dengan mana panas mengalir dari daerah yang bersuhu lebih tinggi ke daerah yang bersuhu lebih rendah di dalam 
suatu medium (padat, cair, gas) atau antara medium-medium yang berlainan yang bersinggungan secara langsung.

Formula :

$$
\mathrm{q}=-\mathrm{k} \cdot \mathrm{A} \cdot \frac{d T}{d x}
$$

dimana:

$$
\begin{aligned}
\mathrm{q} & =\text { Laju perpindahan kalor }(\mathrm{W}) \\
\mathrm{k} & =\text { Konduktivitas termal }\left(\mathrm{W} / \mathrm{m}^{\circ} \mathrm{C}\right) \\
\mathrm{A} & =\text { Luasan }\left(\mathrm{m}^{2}\right) \\
\frac{d T}{d x} & =\text { gradien suhu }
\end{aligned}
$$

Konduksi satu-satunya mekanisme dengan mana panas dapat mengalir dalam zat padat yang tidak tembus cahaya. Konduksi dalam fluida (dalam medium yang bukan padat) tergabung dengan konveksi, dan beberapa hal juga dengan radiasi.

\section{b. Konveksi}

Adalah proses transpot energi dengan kerja gabungan dari konduksi panas, penyimpanan energi dan gerakan mencampur. Konveksi sangat penting sebagai mekanisme perpindahan energi antara permukaan benda padat, cair, dan gas.

Mekanisme fisis perpindahan kalor konveksi berhubungan dengan proses konduksi. Guna menyatakan pengaruh konduksi secara menyeluruh kita gunakan hukum Newton tentang pendinginan :

Rumus untuk perpindahan panas konveksi,

$$
\begin{aligned}
\mathrm{q}=\text { h.A. } & \left(\mathrm{T}_{\mathrm{w}}-\mathrm{T}_{\infty}\right) \ldots \ldots \ldots \ldots \ldots \ldots \ldots . . .(2) \\
& \operatorname{dimana:} \\
\mathrm{q} & \text { Laju perpindahan kalor }(\mathrm{W}) \\
\mathrm{h} \quad & \text { Koefisien perpindahan kalor } \\
& \text { konveksi }\left(\mathrm{W} / \mathrm{m}^{20} \mathrm{C}\right) \\
\mathrm{A} \quad= & \text { Luas Permukaan }\left(\mathrm{m}^{2}\right) \\
\mathrm{T}_{\mathrm{w}} \quad= & \text { Suhu dinding }\left({ }^{\circ} \mathrm{C}\right) \\
\mathrm{T}_{\infty} \quad= & \text { Suhu Fluida }\left({ }^{\circ} \mathrm{C}\right)
\end{aligned}
$$

\section{c. Radiasi}

Adalah proses dengan mana panas mengalir dari benda yang bersuhu tinggi ke benda yang bersuhu rendah bila bendabenda itu terpisah di dalam ruang, bahkan bila terdapat ruang hampa diantara bendabenda tersebut. Istilah radiasi biasa dipakai dalam gelombang elektromagnetik. Dalam ilmu perpindahan panas perlu memperhatikan hal-ikhwal yang diakibatkan oleh suhu dan yang dapat mengangkut energi melalui medium yang tembus cahaya atau melalui ruang. Energi ini diistilahkan panas radiasi.

\section{Konduktivitas Termal}

Adalah sifat bahan dan menunjukkan jumlah panas yang mengalir melintasi satu satuan luas jika gradien suhunya satu. Bahan yang mempunyai konduktivitas termal yang tinggi dinamakan konduktor, sedangkan bahan yang konduktivitas termalnya rendah disebut isolator. Konduktivitas termal berubah dengan suhu, tetapi dalam banyak soal perekayasaan perubahannya cukup kecil untuk diabaikan.

Nilai angka konduktivitas termal itu menunjukkan berapa cepat kalor mengalir dalam bahan tertentu. Makin cepat molekul bergerak, makin cepat pula ia mengangkut energi. Jadi konduktivitas termal bergantung pada suhu. Indeks (k) menunjukkan bahwa mekanisme perpindahannya dengan cara konduksi.

\section{Refraktori}

Ada baiknya bahan-bahan isolator dikelompokkan menurut penerapan dan jangkauan suhu penggunaanya. Dalam operasi reaktor di HYL III DR Plant bahan isolasi yang digunakan adalah refraktori khusus untuk industri baja. Refraktori ini akan dipasang pada reaktor sebagai insulator agar kerugian panas terlalu besar tidak terjadi.

Refraktori adalah suatu bahan yang mempunyai sifat dapat mempertahankan bentuknya pada temperatur tinggi, karena itu banyak digunakan sebagai bahan pelapis tanur (isolator) untuk proses-proses yang 
memerlukan temperatur tinggi. Baik buruknya (kualitas) suatu refraktori terutama ditentukan oleh bahan baku dan cara pembuatannya. Bahan baku yang digunakan berupa bahan anorganik non logam yang dapat diperoleh dari bahan galian alam yang berfasa padat atau bahan anorganik artifisial (umumnya berupa oksida-oksida logam).

Selain berfungsi sebagai wadah dari bahan yang dipanaskan, fungsi utama adalah sebagai penyekat panas sehingga bahan-bahan yang diproses dengan panas tersebut dapat terjadi secara sempurna.

Sifat-sifat panas yang harus dimiliki adalah sebagai berikut :

1. Tahan terhadap temperatur tinggi (tidak melebur).

2. Tahan terhadap beban struktur/konstruk si/berat isi tungku pada temperatur tertentu.

3. Memiliki stabilitas volume pada temperatur kerja.

4. Tahan terhadap kejut suhu atau perubahan temperatur secara tiba-tiba.

5. Memiliki sifat isolasi panas yang tinggi.

6. Tahan terhadap reaksi kimia/fisika/mekanis pada temperatur kerja.
Pada industri besi baja refraktori yang digunakan adalah ; jenis basa (magnesit, chrom magnesit, dolomit semi stabil/stabil dan chrom magnesit), jenis kadar alumina tinggi $50-80 \% \mathrm{Al}_{2} \mathrm{O}_{3}$ dan jenis samot baik formed maupun unformed.

\section{METODE PEMECAHAN MASALAH Objek Kajian}

Objek kajian adalah sebuah reactor 421D1 HYL III Direct Reduction Plant PT. KRAKATAU STEEL pada Isobaric zone sebagai zona untuk mereduksi bijih besi (iron ore) menjadi besi spons (sponge iron).

\section{Teknik Penyediaan Data}

Penyediaan data dalam penelitian ini menggunakan teknik studi literatur dan inspeksi ke lapangan. Data yang dikumpulkan adalah data yang berhubungan dengan sistem yang terjadi di reactor 421-D1 HYL III Direct Reduction Plant PT. KRAKATAU STEEL pada Isobaric Zone.

\section{Kerangka Penyelesaian Masalah}

Alur untuk menyelesaikan masalah dapat dilihat dalam gambar 1 sebagai berikut :

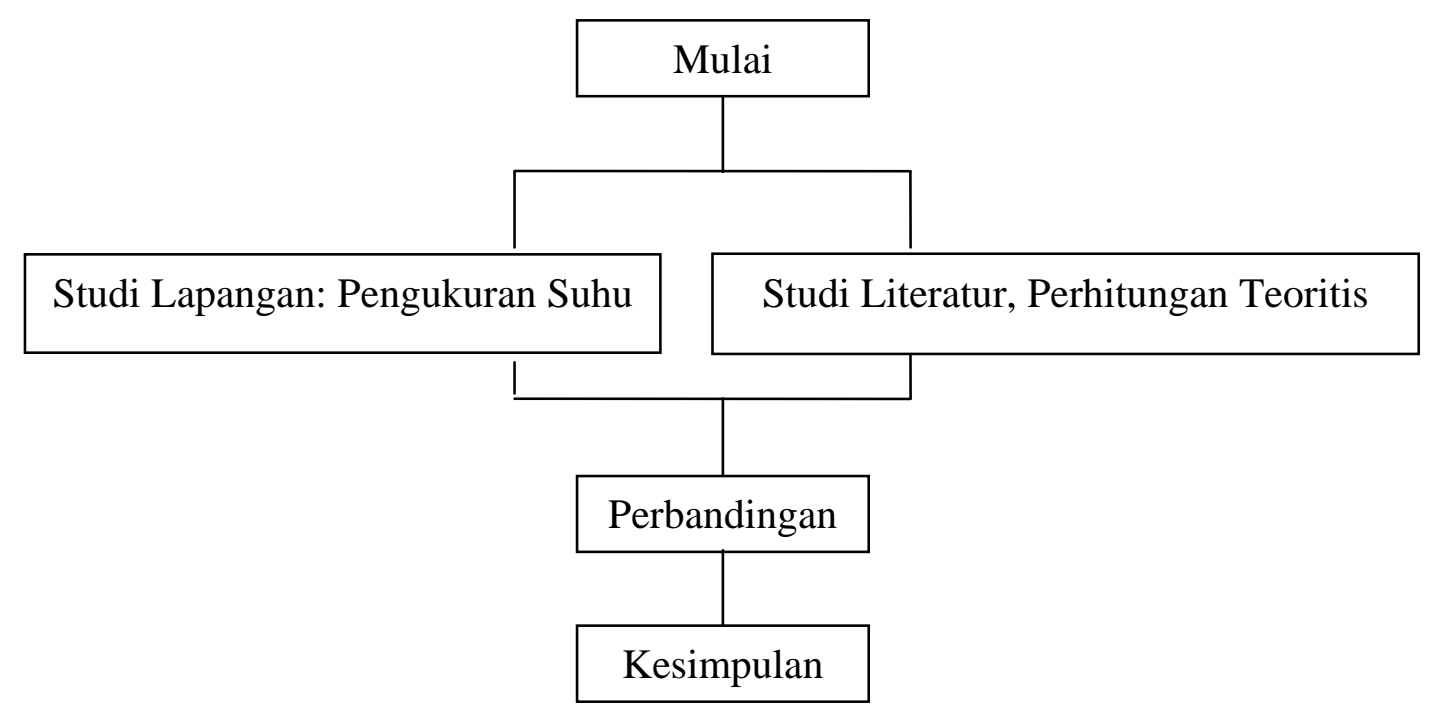

Gambar 1 Alur penyelesaian masalah 


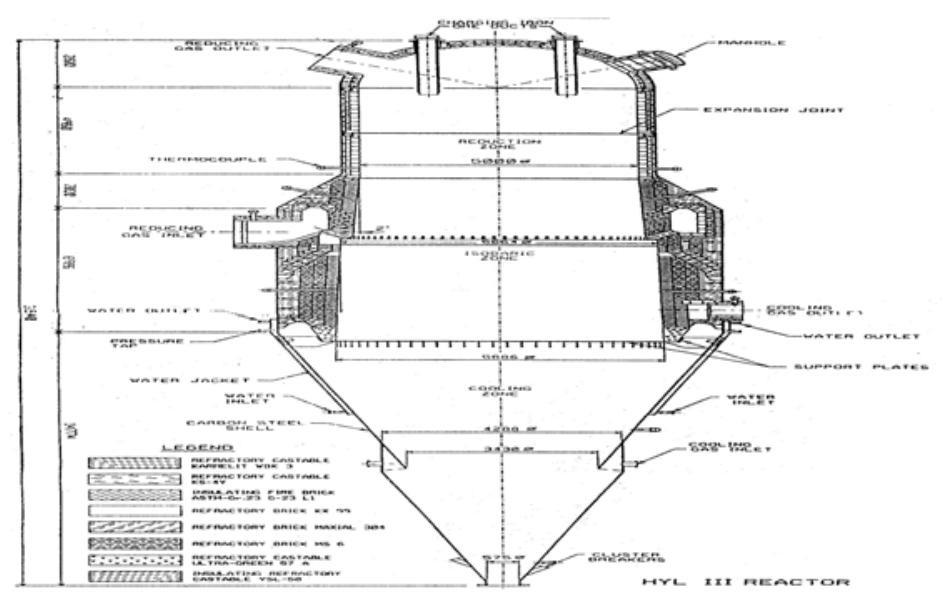

Gambar 2 Reactor 421-D1 daerah isobaric

\section{HASIL DAN PEMBAHASAN \\ Perhitungan Teoritis \\ Pemodelan}

Gambar reactor dapat dilihat pada gambar 2, sedang pemodelan perpindahan panas pada daerah isobaric zone dapat dilihat dalam gambar 3

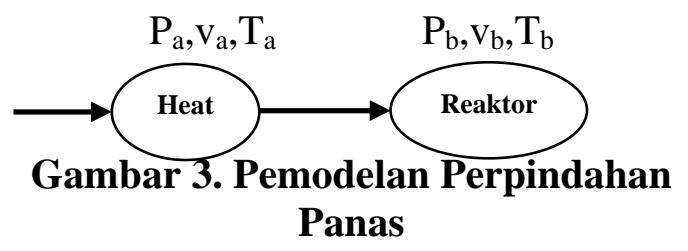

Proses reduksi menggunakan gas reduksi $\mathrm{H}_{2} \mathrm{O}, \mathrm{H}_{2}, \mathrm{CO}, \mathrm{CO}_{2}, \mathrm{~N}_{2}, \mathrm{CH}_{4}$ dengan masing-masing mempunyai prosentase. Untuk gas $\mathrm{H}_{2}$ mempunyai $88 \%$ volume flow dari total keseluruhan. Karena gas $\mathrm{H}_{2}$ mendominasi prosentase dari total volume flow, maka hanya akan dianalisa pada gas $\mathrm{H}_{2}$ saja.

\section{Data-Data Perhitungan}

Data-data yang diperoleh di lapangan adalah sebagai berikut :

$\mathrm{P}_{\mathrm{a}}=4,55 \mathrm{~kg} / \mathrm{cm}^{2}$ [inlet pressure gas heater] $\mathrm{P}_{\mathrm{a}}=\mathrm{P}_{\mathrm{b}}$

$\mathrm{T}_{\mathrm{a}}=38,93{ }^{\circ} \mathrm{C}$ [inlet temperature gas heater] $\mathrm{T}_{\mathrm{b}}=1350^{\circ} \mathrm{C}=1623 \mathrm{~K}$ [outlet temperature gas heater] $\mathrm{v}_{\mathrm{a}}=\mathrm{v}_{\mathrm{b}}$ [volume flow on NCMH]

\section{Analisis Gas $\mathbf{H}_{2}$}

Volume gas $\mathrm{H} 2$ di dalam reactor adalah $88 \%$ dengan laju aliran gas adalah 150000 $\mathrm{NCMH}$.

Temperatur pada Isobaric Zone adalah $1000{ }^{\mathrm{O}} \mathrm{C}$

Komposisi volume $\mathrm{H}_{2}$

$$
\begin{aligned}
& \frac{88}{100} \times 150000=132000 \mathrm{NCMH} \\
& \mathrm{V}_{\mathrm{b}}= \frac{132000}{60 \times 60}=\frac{132000}{3600}=36,67 \mathrm{NCMS} \\
& \mathrm{P}_{\mathrm{b}}= 4,55 \mathrm{~kg} / \mathrm{cm}^{2} \\
& \mathrm{~T}_{\mathrm{b} 1}=1000+273=1273 \mathrm{~K} \\
& {[\text { temperatur gas in isobaric zone }] } \\
& \mathrm{V}_{\mathrm{b} 1}=\frac{1}{4,55} \times \frac{1623}{1273} \times 36,67 \\
&= \frac{59515,41}{5792,15} \\
&= 10,27 \mathrm{CMS}
\end{aligned}
$$

[volume flow on CMS (cubic metre sekon)]

Dengan cara interpolasi Rapat massa $(\rho)$ dari $\mathrm{H}_{2}$ dengan suhu $1350^{\circ} \mathrm{C}$ dapat diketahui sebesar $0,0154 \mathrm{~m}^{3} / \mathrm{kg}$. Dengan cara interpolasi Kalor jenis (c) dari $\mathrm{H}_{2}$ dengan suhu $1350^{\circ} \mathrm{C}$ dapat diketahui sebesar $16,26 \mathrm{~J} / \mathrm{kg}$. K 


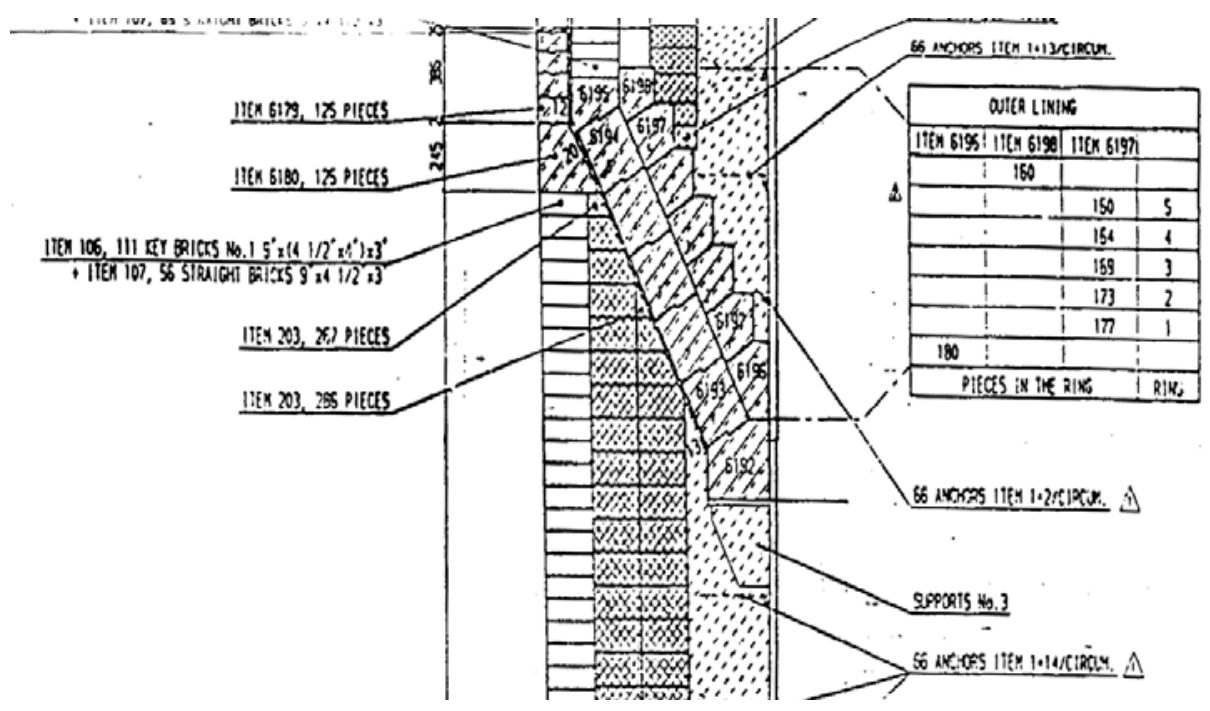

Gambar 4. Susunan bahan refraktori pada Isobaric Zone

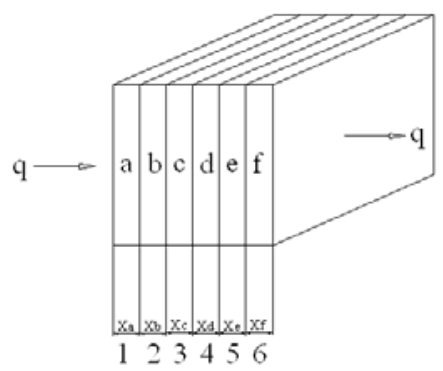

Gambar 5.Pemodelan Lapisan refraktori

Bahan isolator refraktori

Bahan refraktori yang ditunjukkan dalam gambar 6, 7 terdiri dari;

a) Refractory Brick KX $99 \mathrm{BF}$

$$
\begin{array}{ll}
\mathrm{k}_{\mathrm{a}} & =1,4 \mathrm{~W} / \mathrm{m} \mathrm{K} \\
\mathrm{x}_{\mathrm{a}} & =229 \mathrm{~mm}
\end{array}
$$

b) Insulating Fire Brick G-23 LI

$$
\begin{array}{ll}
\mathrm{k}_{\mathrm{b}} & =0,22 \mathrm{~W} / \mathrm{m} \mathrm{K} \\
\mathrm{x}_{\mathrm{b}} & =100 \mathrm{~mm}
\end{array}
$$

c) Refractory Brick Maxial 304

$$
\begin{array}{ll}
\mathrm{k}_{\mathrm{c}} & =1,4 \mathrm{~W} / \mathrm{m} \mathrm{K} \\
\mathrm{x}_{\mathrm{c}} & =100 \mathrm{~mm}
\end{array}
$$

d) Refractory Brick Maxial 304

$$
\mathrm{k}_{\mathrm{d}}=1,4 \mathrm{~W} / \mathrm{m} \mathrm{K}
$$

$\mathrm{x}_{\mathrm{d}}=100 \mathrm{~mm}$

e) Insulating Castable VSL 50

$\mathrm{k}_{\mathrm{e}}=0,32 \mathrm{~W} / \mathrm{m} \mathrm{K}$

$\mathrm{x}_{\mathrm{e}}=100 \mathrm{~mm}$

f) Plat RX ASTM A-515 Gr 70 (Carbon Steel)

$\mathrm{k}_{\mathrm{d}}=43 \mathrm{~W} / \mathrm{m} \mathrm{K}$

$\mathrm{x}_{\mathrm{d}}=38 \mathrm{~mm}$

Asumsi :

1. kondisi 1 dimensi.

2. keadaan steady state. 
Laju Kalor (q) yang diberikan heater ke reaktor adalah :

$$
\begin{aligned}
\mathrm{q} & =\rho \cdot \mathrm{c} \cdot \mathrm{v}_{2 \mathrm{a}} \cdot \Delta \mathrm{T} \ldots \ldots \ldots \ldots \ldots(3) \\
& =0,0154 \cdot 16,26 \cdot 10,27(1350-1000) \\
& =900,07 \text { Watt }
\end{aligned}
$$

Temperatur dinding luar $\left(\mathrm{T}_{6}\right)$ adalah :

$$
\mathrm{q}=\frac{T_{1}-T_{6}}{\frac{\Delta x_{a}}{k_{a} A}+\frac{\Delta x_{b}}{k_{b} \cdot A}+\frac{\Delta x_{c}}{k_{c} \cdot A}+\frac{\Delta x_{d}}{k_{d} \cdot A}+\frac{\Delta x_{e}}{k_{e} \cdot A}+\frac{\Delta}{k_{f} A}} \ldots \ldots(
$$

Dari perhitungan yang menggunakan persamaan 4 maka didapatkan besarnya $\mathrm{T}_{6}$ yaitu sebesar $36,93{ }^{\circ} \mathrm{C}$.

Dari hasil analisa secara teoritis temperatur pada dinding luar reaktor $\left(\mathrm{T}_{6}\right)$ adalah sebesar $36,93{ }^{\circ} \mathrm{C}$, sedangkan pada pengukuran di lapangan suhu pada daerah isobaric mencapai angka $150^{\circ} \mathrm{C}$. Dari hasil tersebut didapatkan perbedaan yang signifikan antara hasil teoritis dengan pengukuran temperatur dinding luar reaktor yang berada di lapangan (kondisi actual).

\section{KESIMPULAN}

Dari hasil pembahasan di atas maka kita dapat membandingkan, ternyata temperatur dinding luar reaktor secara teoritis adalah 36,93 ${ }^{\mathrm{O}} \mathrm{C}$. Hal ini jauh berbeda dengan temperatur dinding luar reaktor di lapangan (kondisi actual) yaitu $150{ }^{\mathrm{O}} \mathrm{C}$. Dapat diambil kesimpulan bahwa sebab terjadinya perbedaan temperatur tersebut adalah adanya panas yang keluar dari dalam reactor sehingga terjadi kerugian panas (heat losses) pada reaktor.

\section{DAFTAR PUSTAKA}

Brown. Royce N., 1986, Compressor Selection \& Sizing, Gulf Publishing Company, Houston, Texas.

; Operaton Manual, Vol. I of III, Divisi Perawatan Pabrik besi Spons HYL III DR Plant PT. Krakatau Steel.

; Operaton Manual; Vol. IV of V, Divisi Perawatan Pabrik besi Spons HYL III DR Plant PT. Krakatau Steel.

Holman, J.P., 1988,Perpindahan Kalor, penterjemah Jasjfi E, Erlangga, Jakarta.

Kreith Frank, Prijono Arko, 1997, Prinsip-prinsip Perpindahan Panas, Erlangga, Jakarta.

Soetjipto, B.R., Basuki A.E., 2004. Kursus Singkat Refraktori Untuk Industri Baja, Departemen Teknik Pertambangan Fakultas Ilmu Kebumian Dan Teknologi Mineral, ITB, Bandung.

Wahyudi Lilik, 2005, Analisis Heat Losses Pada Reaktor Hyl III Direct Reduction Plant akibat Penurunan Performansi Refraktori Pt Krakatau Steel (Persero), Laporan Kerja Praktek, Jurusan Teknik Mesin Universitas Muhammadiyah Surakarta, Surakarta 